\title{
Effects of short-term application of low-dose growth hormone on trace element metabolism and blood glucose in surgical patients
}

\author{
Kun Qian, Zhi Wan, Lang-Song Hao, Ming-Ming Zhang, Yong Zhou, Xiao-Ting Wu
}

Kun Qian, Lang-Song Hao, Ming-Ming Zhang, Yong Zhou, Xiao-Ting Wu, Department of General Surgery, West China Hospital, Sichuan University, Chengdu 610041, Sichuan Province, China

Zhi Wan, Pediatrics, West China Second Hospital, Sichuan University, Chengdu 610041, Sichuan Province, China

Correspondence to: Professor Xiao-Ting Wu, Department of General Surgery, West China Hospital, Sichuan University, 37 Guo Xue Road, Chengdu 610041, Sichuan Province,

China. hxjsqk@163.com

Telephone: +86-13980523523 Fax: +86-288-5422483

Received: June 14, 2007 Revised: October 8, 2007

\begin{abstract}
AIM: To investigate the effects of short-term application of low-dose growth hormone on trace element metabolism and blood glucose in surgical patients
\end{abstract}

METHODS: A total of 48 consecutive patients undergoing abdominal operations were randomized to receive either subcutaneous $\mathrm{hhGH}(0.15 \mathrm{IU} / \mathrm{kg})$ or placebo (menstruum) injections daily for $7 \mathrm{~d}$ after surgery. The two groups had similar nutrition intake. Blood, feces, urine and drain samples were collected to measure zincum, cuprum and ferrum as well as glucose levels. Accumulative intake, excretion and balance of zincum, cuprum and ferrum, apparent absorption (AA) and apparent utilization (AU) of zincum, cuprum and ferrum, blood glucose levels and adverse events were estimated.

RESULTS: There were no differences in accumulative intake and drain excretion between the two groups. The feces excretion and accumulative excretion of cuprum were lower in the rhGH group $(P<0.05)$. The urinary excretion of zincum, cuprum and ferrum was all significantly decreased in the rhGH group $(P<0.05)$ and the accumulative balance of zincum, cuprum and ferrum was improved compared with the placebo group $(P<0.05)$. AA of cuprum in the rhGH group was almost twice as much as the placebo group $(P<0.05)$, and AU of zincum, cuprum and ferrum was all improved in the rhGH group $(P<0.05)$. The mean blood glucose level was significantly higher in the rhGH group than in the placebo group from d 3 to d 6 after operation $(P<0.05)$.

CONCLUSION: Postoperative low-dose rhGH treatment improves the retention of zincum, cuprum and ferrum and decreases the excretion of zincum, cuprum and ferrum, improves the balance of zincum, cuprum and ferrum, and promotes the AA and AU of zincum, cuprum and ferrum. rhGH can be well tolerated without significant adverse effects and the blood glucose level can be well controlled.

\section{(c) 2007 WJG. All rights reserved.}

Key words: Growth hormone; Metabolism; Trace elements; Zincum; Cuprum; Ferrum

Qian K, Wan Z, Hao LS, Zhang MM, Zhou Y, Wu XT. Effects of short-term application of low-dose growth hormone on trace element metabolism and blood glucose in surgical patients. World J Gastroenterol 2007; 13(46): 6259-6263

http://www.wjgnet.com/1007-9327/13/6259.asp

\section{INTRODUCTION}

Patients undergoing abdominal surgery often suffer from severe trauma or infection caused by catabolic responses ${ }^{[1]}$, which cannot be prevented by conventional parenteral or enteral nutrition formulas ${ }^{[2,3]}$. Administration of recombinant human growth hormone (rhGH) has been shown to significantly maintain the nitrogen balance and increase the protein synthesis in surgical patients receiving either parenteral or enteral nutrition ${ }^{[4-7]}$. Most of such studies paid more attention to nitrogen balance and protein metabolism changing associated with rhGH treatment. However, there are few studies focusing on the effects of rhGH on trace element metabolism in patients. The present study was to evaluate the effects of rhGH on trace element metabolism and blood glucose levels in selective abdominal surgical patients.

\section{MATERIALS AND METHODS}

\section{Patients}

The study was conducted in accordance with the guidelines for Good Clinical Practice and the provisions of the Declaration of Helsinki in 1995 as revised in Edinburgh 2000, and approved by the Ethical Review Committee of West China Hospital. Only those who consented to 
participate in the study after explanation of the objectives and protocol were included in the study. Signed, informed consent was obtained from all patients and their close relatives.

Forty-eight adult patients were enrolled in the study and all met the following criteria: undergoing a selective abdominal operation, aged 18-75 years, willing and being able to comprehend the protocol and give written informed consent. Exclusion criteria were as follows: severe bacterial infection, liver and renal dysfunction, previous or current treatment with corticosteroids, diabetis mellitus or fasting glucose levels greater than or equal to $7.0 \mathrm{mmol} / \mathrm{L}$, metabolic diseases, gestation, severe malnutrition (serum albumin $<21 \mathrm{~g} / \mathrm{L}$ ), tumor recrudescence or metastasis.

\section{Study design}

The study was a randomized prospective double-blind, placebo-controlled clinical trial. Eligible patients were randomly assigned to rhGH group or placebo group (24 each group). The randomization codes were prepared with the random number table according to the design of a computer. Patients, surgeons and nursing staff members remained blind to the allocation status of the study drugs throughout the experiment.

After operation, all patients received continuous combined intravenous or/and enteral nutrition. The daily total caloric requirement was $20 \mathrm{kcal} / \mathrm{kg}$ and total nitrogen requirement was $140 \mathrm{mg}$ of nitrogen $/ \mathrm{kg}$. Parenteral nutrition (PN) solution was prepared aseptically using commercially available products, including vitamins, trace elements and electrolytes (Addamel, Vitlipid, Soluvit and Glycophos; Fresenius Kabi Deutschland Gmbh, Bad Homburg, Germany). Amino acid injections were provided as $8.5 \%$ and $11.4 \%$ Novamin (Fresenius Kabi Deutschland Gmbh). Energy calories were provided with glucose and fat emulsion injections (50\% glucose and 20\% Lipovenos ${ }^{\circledR}$ MCT; Fresenius Kabi Deutschland Gmbh). All the nutrients were given in all-in-one bag. Enteral nutrition (EN) emulsion (Fresenius Kabi Deutschland Gmbh) was provided orally or via a nasogastric tube with a continuous perfusion pump.

Postoperatively, patients received general intravenous infusion with only glucose on d 1; PN provided only half of total caloric and nitrogen requirement on $\mathrm{d} 2$ and all of total requirement on $\mathrm{d} 3$; on $\mathrm{d} 4, \mathrm{PN}$ provided $2 / 3$ of total requirement and EN provided another $1 / 3$; on $\mathrm{d} 5, \mathrm{PN}$ provided $1 / 3$ of total requirement and EN provided 2/3; only EN emulsion was given from d 6 to $\mathrm{d} 9$.

From d 3 to d 10 post operation, patients were randomly assigned to receive identical-looking treatments consisting of either rhGH (JINTROPIN ${ }^{\circledR}, 0.15 \mathrm{mg} / \mathrm{kg}$ ) or menstruum injection ( $1 \mathrm{~mL}$, consisting of glycin, mannitol, lactose and sodium bicarbonate) subcutaneously once daily. rhGH and placebo were provided by GeneScience Pharmaceutical Co. Ltd, Changchun, China.

\section{Laboratory tests}

Blood samples were drawn from each patient before operation to measure baseline values and on $\mathrm{d} 3$ and 10 after operation to study the rhGH effect. Complete blood
Table 1 Baseline characteristics of patients (mean \pm SD)

\begin{tabular}{lccl}
\hline Variable & Placebo $(\boldsymbol{n}=\mathbf{2 4})$ & rhGH $(\boldsymbol{n}=\mathbf{2 4})$ & $\boldsymbol{P}$ \\
\hline Age (yr) & $58.50 \pm 9.35$ & $59.08 \pm 10.93$ & 0.789 \\
& $39-75$ & $35-74$ & \\
Sex (femal/male) & $11 / 13$ & $9 / 15$ & 0.558 \\
Weight $(\mathrm{kg})$ & $57.90 \pm 8.42$ & $56.19 \pm 11.83$ & 0.567 \\
Height $(\mathrm{cm})$ & $162.42 \pm 6.92$ & $162.88 \pm 7.16$ & 0.823 \\
Sepsis score & $0.79 \pm 0.98$ & $0.67 \pm 0.87$ & 0.742 \\
Operation position, $n(\%)$ & & & \\
$\quad$ Resection of stomach & $6(25)$ & $5(20.8)$ & 0.297 \\
$\quad \begin{array}{l}\text { Resection of colon } \\
\text { Resection of rectum }\end{array}$ & $5(20.8)$ & $7(29.2)$ & \\
$\quad$ Others & $12(50)$ & $9(37.5)$ & \\
$\begin{array}{l}\text { Acumulative intakes of } \\
\text { energy (10 }{ }^{3} \text { kcal) }\end{array}$ & $7.98 \pm 0.67$ & $3(12.5)$ & \\
Acumulative intakes of & $54.84 \pm 5.23$ & $53.76 \pm 0.76$ & 0.292 \\
nitrogen (g) & & & \\
\hline
\end{tabular}

cell count was estimated by the XE-2100 (Sysmex, Kobe, Japan). Plasma glucose, serum urea nitrogen, creatinine, bilirubin, alanine aminotransferase, alkaline phosphatase, total protein, albumin and electrolytes were estimated using an Olympus AU5400 autoanalyser (Olympus, Tokyo, Japan).

\section{Trace element balance}

Daily trace element input was assumed to be the trace element contents (zincum, cuprum, ferrum) in PN/or EN solution given. Daily trace element loss was assessed by collecting 24-h output and measuring the trace element contents in feces, urine and drains. Accumulated trace element balance was calculated by subtracting $7 \mathrm{~d}$ trace element output from $7 \mathrm{~d}$ trace element input. Trace element contents in samples were determined by the inductively coupled plasma atomic emission spectrometry (ICPAES) and estimated by the IRIS ADVANTAGE 1000 (Thermo Elemental, USA).

\section{Statistical analysis}

All data were assessed for normality of distribution and equality of variance. Student's $t$-test and multiple correlation analysis were used to compare normal distribution of data. Data are presented throughout as mean $\pm S D$. All data analyses were performed using the program SPSS 11.5 for Windows. $P<0.05$ was considered statistically significant.

\section{RESULTS}

\section{Patient characteristics}

There was no difference in baseline characteristics between the two groups (Table 1).

\section{Accumulative intake, excretion and balance of zincum, cuprum and ferrum}

As shown in Table 2, there were no differences in accumulative intake and drain excretion between the two groups. The feces excretion and accumulative excretion of cuprum were lower in the rhGH group. The urinary excretion of zincum, cuprum and ferrum was 
Table 2 Accumulative intake, excretion and balance of zincum, cuprum and ferrum

\begin{tabular}{|c|c|c|c|c|c|c|}
\hline \multirow[t]{2}{*}{ Test } & \multicolumn{2}{|c|}{ Zincum } & \multicolumn{2}{|c|}{ Cuprum } & \multicolumn{2}{|c|}{ Ferrum } \\
\hline & Placebo $(n=24)$ & rhGH $(n=24)$ & Placebo $(n=24)$ & rhGH $(n=24)$ & Placebo $(n=24)$ & rhGH $(n=24)$ \\
\hline Accumulative intake (mg) & $65.79 \pm 6.38$ & $71.92 \pm 6.96$ & $10.01 \pm 0.85$ & $10.82 \pm 0.92$ & $65.08 \pm 8.50$ & $73.25 \pm 9.29$ \\
\hline Urinary excretion (mg) & $36.74 \pm 5.76$ & $32.51 \pm 5.55^{\mathrm{a}}$ & $0.37 \pm 0.08$ & $0.28 \pm 0.05^{\mathrm{a}}$ & $18.65 \pm 5.99$ & $12.10 \pm 3.92^{\mathrm{a}}$ \\
\hline Feces excretion (mg) & $19.14 \pm 6.49$ & $18.07 \pm 7.50$ & $4.21 \pm 1.00$ & $1.74 \pm 0.95^{\mathrm{a}}$ & $22.38 \pm 9.82$ & $19.65 \pm 3.71$ \\
\hline Drain excretion (mg) & $2.74 \pm 0.48$ & $2.48 \pm 0.62$ & $0.84 \pm 1.00$ & $0.61 \pm 0.05$ & $14.83 \pm 4.05$ & $16.69 \pm 3.32$ \\
\hline Accumulative excretion (mg) & $58.62 \pm 8.69$ & $53.06 \pm 9.35$ & $5.42 \pm 1.42$ & $2.63 \pm 0.95^{\mathrm{a}}$ & $55.86 \pm 12.19$ & $48.44 \pm 6.34$ \\
\hline Accumulative balance (mg) & $7.17 \pm 5.90$ & $18.86 \pm 6.24^{\mathrm{a}}$ & $4.59 \pm 1.33$ & $8.19 \pm 0.28^{\mathrm{a}}$ & $9.22 \pm 8.74$ & $24.81 \pm 6.79^{\mathrm{a}}$ \\
\hline
\end{tabular}

${ }^{\mathrm{a}} P<0.05$ vs placebo group.

Table 3 Comparison between apparent absorption (AA) and apparent utilization (AU) of zincum, cuprum and ferrum (mean \pm SD)

\begin{tabular}{|c|c|c|c|c|c|c|}
\hline \multirow[t]{2}{*}{ Test } & \multicolumn{2}{|c|}{ Zincum } & \multicolumn{2}{|c|}{ Cuprum } & \multicolumn{2}{|c|}{ Ferrum } \\
\hline & Placebo $(n=24)$ & rhGH $(n=24)$ & Placebo $(n=24)$ & rhGH $(n=24)$ & Placebo $(n=24)$ & rhGH $(n=24)$ \\
\hline Accumulative intake (mg) & $65.79 \pm 6.38$ & $71.92 \pm 6.96$ & $10.01 \pm 0.85$ & $10.82 \pm 0.92$ & $65.08 \pm 8.50$ & $73.25 \pm 9.29$ \\
\hline Accumulative intake of EN (mg) & $46.29 \pm 6.38$ & $52.42 \pm 6.96$ & $6.17 \pm 0.85$ & $6.98 \pm 0.92$ & $61.72 \pm 8.50$ & $69.89 \pm 9.29$ \\
\hline Urinary excretion (mg) & $36.74 \pm 5.76$ & $32.51 \pm 5.55$ & $0.37 \pm 0.08$ & $0.28 \pm 0.05$ & $18.65 \pm 5.99$ & $12.10 \pm 3.92$ \\
\hline Feces excretion (mg) & $19.14 \pm 6.49$ & $18.07 \pm 7.50$ & $4.21 \pm 1.00$ & $1.74 \pm 0.95^{\mathrm{a}}$ & $22.38 \pm 9.82$ & $19.65 \pm 3.71$ \\
\hline Apparent absorption (\%) & $59.09 \pm 10.56$ & $66.25 \pm 11.07$ & $31.80 \pm 13.78$ & $75.21 \pm 13.69^{\mathrm{a}}$ & $64.94 \pm 11.72$ & $71.87 \pm 4.00$ \\
\hline Apparent utilization (\%) & $15.21 \pm 5.43$ & $30.02 \pm 6.23^{\mathrm{a}}$ & $54.35 \pm 8.87$ & $81.36 \pm 8.57^{\mathrm{a}}$ & $37.31 \pm 6.85$ & $56.34 \pm 6.99^{\mathrm{a}}$ \\
\hline
\end{tabular}

${ }^{a} P<0.05$ vs placebo group.

Table 4 Comparison of blood glucose levels

\begin{tabular}{lcccccccc}
\hline Test & D1 & D3 & D4 & D5 & D6 & D7 & D8 & D9 \\
\hline Glucose (mmol/L) & & & & & & & & \\
Placebo & $5.26 \pm 1.09$ & $5.68 \pm 1.33$ & $5.81 \pm 1.56$ & $5.84 \pm 1.48$ & $5.95 \pm 2.34$ & $6.01 \pm 2.64$ & $5.66 \pm 2.03$ & $5.70 \pm 1.89$ \\
rhGH & $5.14 \pm 0.64$ & $6.71 \pm 1.93^{\mathrm{a}}$ & $7.17 \pm 1.86^{\mathrm{a}}$ & $8.28 \pm 2.30^{\mathrm{a}}$ & $7.68 \pm 2.15^{\mathrm{a}}$ & $7.29 \pm 2.93$ & $6.40 \pm 2.00$ & $6.20 \pm 2.13$ \\
\hline
\end{tabular}

${ }^{\mathrm{a}} P<0.05$ vs placebo group.

\section{Table 5 Main adverse events}

\begin{tabular}{lcc}
\hline Event & Placebo & rhGH \\
\hline Hyperglycemia & 4 & $23^{\mathrm{a}}$ \\
Tetter & 1 & 0 \\
Sepsis & 0 & 0 \\
Infection & 2 & 3 \\
Death & 0 & 0 \\
\hline
\end{tabular}

${ }^{\mathrm{a}} P<0.05$ vs placebo group.

all significantly decreased in the rhGH group and the accumulative balance of zincum, cuprum and ferrum was significantly improved compared with the placebo group.

\section{Apparent absorption (AA) and apparent utilization (AU) of zincum, cuprum and ferrum}

The cuprum was mostly excreted via feces. AA of cuprum in the rhGH group was almost twice as much as that in the placebo group, and AU of zincum, cuprum and ferrum was improved in the rhGH group (Table 3).

\section{Blood glucose levels and adverse events}

The main adverse effects seen during the study are summarized in Tables 4 and 5. The mean blood glucose level was significantly higher in the rhGH group than in the control group from d 3 to d 6 after operation (Table 4). Twenty-there patients in the rhGH group experienced hyperglycemia and 5 of them required insulin treatment (Table 5). Furthermore, 3 patients had other mild adverse events (1 with edema, 1 with tetter and 1 with fever). In the placebo group, 3 of 4 patients presenting hyperglycemia required insulin treatment. Five placebo-treated patients experienced mild electrolyte imbalance, which was not related the trial drug used. There was no significant difference in complete blood cell count, liver and renal function, body weight and daily clinical parameters such as temperature, blood pressure, and pulse, between the two groups.

\section{DISCUSSION}

Many attempts have been made to reverse the catabolic changes that occur in postoperative patients. Conventional nutrition support is unable to provide adequate nutritional supplements to increase or even maintain body proteins and trace elements in hypercatabolic response conditions ${ }^{[8-10]}$. Recent studies indicate that rhGH can stimulate body protein synthesis and produce nitrogenspacing effects ${ }^{[11-13]}$. However, the impact of rhGH on body trace elements and blood glucose has not been 
investigated in patients receiving $\mathrm{PN}$ or EN following selective gastrointestinal surgery ${ }^{[14-16]}$. In the present experiments, we studied the effects of $\mathrm{rhGH}$ on trace element metabolism and blood glucose. The number of patients enrolled in the study was based on previous experiments and the dosage of rhGH used ${ }^{[7,17,18]}$.

Massive trace elements are lost after selective operation because of decreased intake, loss from wound surface, redistribution in the body and increased urinary excretion ${ }^{[19,20]}$. Even supplying adequate nutritional support cannot prevent such a massive loss of trace elements. Zincum, cuprum and ferrum are very important trace elements in the human body and can sensitively reflect changes in gastric diseases ${ }^{[21]}$. In this study, low-dose rhGH treatment reduced the urinary excretion of zincum, cuprum and ferrum, thus improving their accumulative balance compared with the placebo group. Meanwhile, the apparent absorption and utilization of zincum, cuprum and ferrum in the rhGH group were also increased. However, the AU of zincum in the rhGH group (30.02\%) was almost two times higher than that in the placebo group. The AU of cuprum and ferrum in the rhGH group was also about 1.5 times higher than that in the placebo group. These data indicate that low-dose rhGH treatment can reduce the excretion of zincum, cuprum and ferrum, increase their utilization, and maintain the retention and balance of zincum, cuprum and ferrum.

Changes in zincum, cuprum and ferrum metabolism are mainly associated with protein synthesis and breakdown. Since proteins are carriers of many trace elements, rhGH may also improve protein synthesis, reduce protein breakdown, promote recovery of intestinal mucosa, increase mucosa thickness, improve intestinal barrier function, and increase absorption of trace elements ${ }^{[22-24]}$. In our study, the apparent absorption and utilization of zincum, cuprum and ferrum were improved in the rhGH group.

It was reported that $\mathrm{GH}$ given during sepsis can impair immune function and result in hyperglycemia, which may explain why acute critically ill patients do not benefit from GH treatment ${ }^{[25,26]}$. However, selective surgical patients can safely administer $\mathrm{GH}$ after the acute inflammatory response stage. rhGH treatment was generally well tolerated with no serious adverse events occurred in our trial. No death occurred in the GH-treated group, confirming its safety. These results are contrary to the increased mortality among critically ill patients treated with $\mathrm{GH}^{[25]}$. We hypothesize that this discrepancy might be due to the difference in study patients. In our study, the patients were selective surgery subjects. rhGH given during the response to stress leads to uncontrolled systemic inflammation in Takala's study ${ }^{[25]}$.

The main adverse event of rhGH treatment is hyperglycemia. Insulin resistance caused by rhGH plays an important role in the elevation of blood glucose. Other reasons include nutrition support and systemic inflammation syndrome ${ }^{[27,28]}$. In our study, hyperglycemia caused by rhGH administration was mild and controlled by insulin. Considering the difference between critically ill patients and selective surgery patients, rhGH seems to be well tolerated after operation.

Since our study included 14 cancer patients in the rhGH group, the potential tumor-promoting effect of
GH should be addressed. In animal models, the role of rhGH administration in promoting tumor recurrence is controversial $^{[29-31]}$. It was reported that $\mathrm{GH}$ could promote host growth selectively and inhibit tumor metastasis ${ }^{[32,33]}$. Only two trials have assessed the impact of $\mathrm{GH}$ on tumor recurrence in humans. Based on 2632 adverse events, the National Cooperative Growth Study analyzed the recurrence of brain tumors in patients receiving long-term $\mathrm{GH}$ replacement, showing that there is no evidence that $\mathrm{GH}$ increases tumor recurrence ${ }^{[34]}$. Only one study has investigated the impact of short-term treatment with three different doses of $\mathrm{GH}$ on long-term tumor recurrence in postoperative cancer patients ${ }^{[35]}$, finding that $35 \% \mathrm{rhGH}$ treated patients have tumor recurrence in comparison to $44 \%$ placebo-treated patients. Based on the above two studies, we believe that when complete resection and appropriate antineoplastic treatment are administered, cancer patients can safely receive short-term GH treatment.

In conclusion, postoperative low-dose rhGH treatment improves the retention and decreases the excretion of zincum, cuprum and ferrum, increases the balance and promotes their apparent absorption and utilization. rhGH is also well tolerated with no significant adverse effects and can control the blood glucose level. A larger trial is required to determine the clinical endpoints such as infection, morbidity, mortality and tumor recurrence.

\section{COMMENTS}

\section{Background}

Patients undergoing abdominal surgery often suffer from severe trauma or infection caused by catabolic responses, which cannot be prevented by conventional parenteral or enteral nutrition formulas. Administration of recombinant human growth hormone (rhGH) has been shown to significantly maintain the nitrogen balance and increase the protein synthesis in surgery patients receiving either parenteral or enteral nutrition.

\section{Research frontiers}

Many studies paid attention to nitrogen balance and protein metabolism associated with rhGH treatment. However, there are few studies focusing on the effects of $\mathrm{GH}$ on trace element metabolism in patients. This study was to evaluate the effects of rhGH on trace element metabolism and blood glucose levels in selective abdominal surgical patients.

\section{Innovations and breakthroughs}

This study evaluated the effects of rhGH on trace element metabolism and blood glucose levels in selective abdominal surgical patients. Postoperative lowdose rhGH treatment improves the retention of zincum, cuprum and ferrum, and decreases their excretion, increases their balance and promotes their apparent absorption and utilization. rhGH is well tolerated with no significant adverse effects and can control the blood glucose level.

\section{Applications}

The results of this study will promote the short-term low-dose rhGH application in clinical practice. Hyperglycemia is the main adverse event of short-term low-dose rhGH treatment.

\section{Terminology}

Biosynthetic human growth hormone, also referred to as recombinant human growth hormone, is also called somatropin and abbreviated as $\mathrm{rhGH}$.

\section{Peer review}

This is the first study analyzing the effects of growth hormone on trace element metabolism and significantly adds our knowledge on the beneficial effect of shortterm $\mathrm{GH}$ application. 


\section{REFERENCES}

1 Hill GL, Douglas RG, Schroeder D. Metabolic basis for the management of patients undergoing major surgery. World J Surg 1993; 17: 146-153

2 Petersson B, Wernerman J, Waller SO, von der Decken A, Vinnars E. Elective abdominal surgery depresses muscle protein synthesis and increases subjective fatigue: effects lasting more than 30 days. Br J Surg 1990; 77: 796-800

3 Perioperative total parenteral nutrition in surgical patients. The Veterans Affairs Total Parenteral Nutrition Cooperative Study Group. N Engl J Med 1991; 325: 525-532

4 Losada F, García-Luna PP, Gómez-Cía T, Garrido M, Pereira JL, Marín F, Astorga R. Effects of human recombinant growth hormone on donor-site healing in burned adults. World J Surg 2002; 26: $2-8$

5 Hammarquist F, Sandgren A, Andersson K, Essén P, McNurlan MA, Garlick PJ, Wernerman J. Growth hormone together with glutamine-containing total parenteral nutrition maintains muscle glutamine levels and results in a less negative nitrogen balance after surgical trauma. Surgery 2001; 129: $576-586$

6 Ziegler TR, Rombeau JL, Young LS, Fong Y, Marano M, Lowry SF, Wilmore DW. Recombinant human growth hormone enhances the metabolic efficacy of parenteral nutrition: a double-blind, randomized controlled study. J Clin Endocrinol Metab 1992; 74: 865-873

7 Jensen MB, Kissmeyer-Nielsen P, Laurberg S. Perioperative growth hormone treatment increases nitrogen and fluid balance and results in short-term and long-term conservation of lean tissue mass. Am J Clin Nutr 1998; 68: 840-846

8 Byrne TA, Morrissey TB, Gatzen C, Benfell K, Nattakom TV, Scheltinga MR, LeBoff MS, Ziegler TR, Wilmore DW. Anabolic therapy with growth hormone accelerates protein gain in surgical patients requiring nutritional rehabilitation. Ann Surg 1993; 218: 400-416; discussion 416-418

9 Vara-Thorbeck R, Guerrero JA, Ruiz-Requena ME, Capitán J, Rodriguez M, Rosell J, Mekinassi K, Maldonado M, Martin $R$. Effects of growth hormone in patients receiving total parenteral nutrition following major gastrointestinal surgery. Hepatogastroenterology 1992; 39: 270-272

10 Kolstad O, Jenssen TG, Ingebretsen OC, Vinnars E, Revhaug A. Combination of recombinant human growth hormone and glutamine-enriched total parenteral nutrition to surgical patients: effects on circulating amino acids. Clin Nutr 2001; 20: 503-510

11 Norrelund H, Moller N, Nair KS, Christiansen JS, Jorgensen JO. Continuation of growth hormone $(\mathrm{GH})$ substitution during fasting in $\mathrm{GH}$-deficient patients decreases urea excretion and conserves protein synthesis. J Clin Endocrinol Metab 2001; 86: 3120-3129

12 Nørrelund H, Nair KS, Jørgensen JO, Christiansen JS, Møller $\mathrm{N}$. The protein-retaining effects of growth hormone during fasting involve inhibition of muscle-protein breakdown. Diabetes 2001; 50: 96-104

13 Carrel AL, Allen DB. Effects of growth hormone on adipose tissue. J Pediatr Endocrinol Metab 2000; 13 Suppl 2: 1003-1009

14 Kissmeyer-Nielsen $\mathbf{P}$, Jensen MB, Laurberg S. Perioperative growth hormone treatment and functional outcome after major abdominal surgery: a randomized, double-blind, controlled study. Ann Surg 1999; 229: 298-302

15 Petersen SR, Holaday NJ, Jeevanandam M. Enhancement of protein synthesis efficiency in parenterally fed trauma victims by adjuvant recombinant human growth hormone. J Trauma 1994; 36: 726-733

16 Biolo G, Iscra F, Bosutti A, Toigo G, Ciocchi B, Geatti O, Gullo A, Guarnieri G. Growth hormone decreases muscle glutamine production and stimulates protein synthesis in hypercatabolic patients. Am J Physiol Endocrinol Metab 2000; 279: E323-E332

17 Vara-Thorbeck R, Guerrero JA, Rosell J, Ruiz-Requena E, Capitán JM. Exogenous growth hormone: effects on the catabolic response to surgically produced acute stress and on postoperative immune function. World J Surg 1993; 17: 530-537; discussion 537-538

18 Chu LW, Lam KS, Tam SC, Hu WJ, Hui SL, Chiu A, Chiu KC, $\mathrm{Ng}$ P. A randomized controlled trial of low-dose recombinant human growth hormone in the treatment of malnourished elderly medical patients. J Clin Endocrinol Metab 2001; 86: 1913-1920

19 Eroian OM, Rozanova NB. [Changes in the concentration of microelements in different body media during general anesthesia and surgery in patients with cancer of the stomach and esophagus]. Anesteziol Reanimatol 1991; (4): 46-49

20 Gao Z, Li L, Zhao L. The clinical and experimental study on postbum metabolic characteristics of zinc,iron and calcium. Clin J Burns 2006; 16:286-288

21 Yin GY, Zhang WN, Shen XJ, Chen Y, He XF. Ultrastructure and molecular biological changes of chronic gastritis, gastric cancer and gastric precancerous lesions: a comparative study. World J Gastroenterol 2003; 9: 851-857

22 Spadoni JM, Aguilar-Nascimento JE, Silva MH, SpadoniNeto B, Costa PA, Aléssio DM. Effects of the combined use of glutamine and growth hormone in the intestinal adaptation after massive resection of the small bowel in rats. Acta Cir Bras 2005; 20: 382-389

23 Ding LA, Li JS, Li YS, Liu FN, Tan L. Prophylactic treatment with growth hormone improves intestinal barrier function and alleviates bacterial translocation in stressed rats. Chin Med J (Engl) 2004; 117: 264-269

24 Jung SE, Youn YK, Lim YS, Song HG, Rhee JE, Suh GJ. Combined administration of glutamine and growth hormone synergistically reduces bacterial translocation in sepsis. $J$ Korean Med Sci 2003; 18: 17-22

25 Takala J, Ruokonen E, Webster NR, Nielsen MS, Zandstra DF, Vundelinckx G, Hinds CJ. Increased mortality associated with growth hormone treatment in critically ill adults. $N$ Engl J Med 1999; 341: 785-792

26 van den Berghe $G$, Wouters $P$, Weekers F, Verwaest $C$, Bruyninckx F, Schetz M, Vlasselaers D, Ferdinande P, Lauwers $\mathrm{P}$, Bouillon R. Intensive insulin therapy in critically ill patients. N Engl J Med 2001; 345: 1359-1367

27 Valera A, Rodriguez-Gil JE, Yun JS, McGrane MM, Hanson RW, Bosch F. Glucose metabolism in transgenic mice containing a chimeric P-enolpyruvate carboxykinase/bovine growth hormone gene. FASEB J 1993; 7: 791-800

28 Ikeda A, Chang KT, Matsumoto Y, Furuhata Y, Nishihara M, Sasaki F, Takahashi M. Obesity and insulin resistance in human growth hormone transgenic rats. Endocrinology 1998; 139: 3057-3063

29 Ng EH, Rock CS, Lazarus D, Staiano-Coico L, Fischer E, Moldawer LL, Lowry SF. Impact of exogenous growth hormone on host preservation and tumor cell-cycle distribution in a rat sarcoma model. J Surg Res 1991; 51: 99-105

30 Wolf RF, Ng B, Weksler B, Burt M, Brennan MF. Effect of growth hormone on tumor and host in an animal model. Ann Surg Oncol 1994; 1: 314-320

31 Akaza H, Matsuki K, Matsushima H, Koiso K, Aso Y. Stimulatory effects of growth hormone on rat bladder carcinogenesis. Cancer 1991; 68: 2418-2421

32 Torosian MH. Growth hormone and prostate cancer growth and metastasis in tumor-bearing animals. J Pediatr Endocrinol 1993; 6: 93-97

33 Bartlett DL, Charland S, Torosian MH. Growth hormone, insulin, and somatostatin therapy of cancer cachexia. Cancer 1994; 73: 1499-1504

34 Maneatis T, Baptista J, Connelly K, Blethen S. Growth hormone safety update from the National Cooperative Growth Study. J Pediatr Endocrinol Metab 2000; 13 Suppl 2: 1035-1044

35 Tacke J, Bolder U, Herrmann A, Berger G, Jauch KW Long-term risk of gastrointestinal tumor recurrence after postoperative treatment with recombinant human growth hormone. JPEN J Parenter Enteral Nutr 2000; 24: 140-144 